\title{
Synchronous lung and liver metastases from medullary thyroid carcinoma
}

\author{
H Yanardag MD ${ }^{1}, C$ Tetikkurt MD², S Tetikkurt MD
}

H Yanardag, C Tetikkurt, S Tetikkurt. Synchronous lung and liver metastases from medullary thyroid carcinoma. Can Respir J 2003;10(1):39-41.

Metastatic disease is one of the most common causes of calcified nodules in the lung or liver. The incidence of calcified metastasis mainly to the lung and liver is high at the initial presentation in patients with medullary thyriod carcinoma. Synchronous calcified metastasis in the lung and liver is reported for the first time. The diagnosis of medullary thyroid carcinoma may be evident from the synchronous presence of miliary calcified nodules in two different sites if they are associated with high concentrations of serum markers.

Key Words: Calcified metastasis; Medullary thyroid carcinoma; Metastasis; Synchronous metastases

\section{Des métastases pulmonaires et hépatiques syn- chrones causées par un carcinome médullaire thyroidien}

RÉSUMÉ : La maladie métastatique est l'une des principales causes de nodules calcifiés dans le poumon ou le foie. En cas de carcinome médullaire thyroïdien, les calcifications métastatiques peuvent s'observer dans le poumon ou le foie. On rend compte pour la première fois d'une métastase calcifiée à la fois dans le poumon et le foie. Le diagnostic de carcinome médullaire thyroïdien peut être mis en évidence en raison de la présence synchrone de nodules calcifiés miliaires dans deux foyers distincts, s'ils s'associent à de fortes concentrations de marqueurs sériques.

\begin{abstract}
A large variety of neoplasms can produce calcified metastases. Calcified nodules seen on chest or abdominal radiographs may resemble tuberculosis or other granulomatous diseases. In the case of medullary thyroid carcinoma, metastatic calcifications may be found in the lung or liver $(1,2)$. A reasonable suspicion of malignancy is necessary for the identification of calcified metastases from medullary thyroid carcinoma because the primary tumour may be clinically occult.

We report a sporadic case of medullary thyroid carcinoma with synchronous calcified miliary lung and liver metastases. To our knowledge, this is the first report in the literature citing synchronous calcified metastasis in medullary thyroid carcinoma.
\end{abstract}

\section{CASE PRESENTATION}

A 25-year-old man was admitted for anorexia, fatigue and diarrhea lasting four months. His personal and family histories were excellent. Physical examination was normal with a blood pressure of 120/80 mmHg. A complete blood count and blood chemistry were within the normal ranges. The serum calcium level was $2.2 \mathrm{mmol} / \mathrm{L}$ and the phosphorus level was $1.1 \mathrm{mmol} / \mathrm{L}$. The erythrocyte sedimentation rate was $42 \mathrm{~mm} / \mathrm{h}$ and a tuberculin test was negative. Recently performed intravenous pyelography radiographs for the right flank pain to investigate nephrolithiasis showed multiple calcific nodules in the liver (Figure 1). Chest x-ray showed miliary calcific opacities in the middle zones of both lungs and there was no calcification in the neck region (Figure 2). Computed tomography (CT) of the thorax revealed numerous calcified small nodules 2 to $4 \mathrm{~mm}$ in diameter throughout the lungs (Figure 3). CT did not show calcification in the thyroid gland. The calcified nodules in the liver measured between 2 and $8 \mathrm{~mm}$. Abdominal CT did not reveal an adrenal mass compatible with pheochromocytoma. Stool examination, colonoscopy, fine needle aspiration biopsy of the liver and fibreoptic bronchoscopic examination were negative. Transbronchial biopsy specimens were not diagnostic. No acid-fast bacilli were seen on stained bronchial washings. Mycobacterial and fungal cultures of the bronchial lavage were negative. Laparoscopic liver biopsy revealed neuroendocrine carcinoma metastasis compatible with medullary thyroid carcinoma. Thyroid scintigraphy showed diffuse hyperplasia and ultrasonography showed a $7 \times 8 \mathrm{~mm}$ nodule in the left lobe of the thyroid gland. Histopathological examination of the resected thyroid tissue revealed medullary thyroid carcinoma. Serum calcitonin and carcinoembryonic antigen were measured to be $1270 \mathrm{ng} / \mathrm{L}$ and $1000 \mu \mathrm{g} / \mathrm{L}$, respectively. The patient was referred to the oncology department for further treatment.

\section{DISCUSSION}

Medullary thyroid carcinoma originating in the thyroid C cells accounts for $5 \%$ to $10 \%$ of all thyroid malignancies (3). The incidence of distant metastases in medullary thyroid carcinoma is high, mainly to the lung and liver. The distant metastases may appear at the time of initial presentation (4).

\footnotetext{
${ }^{1}$ Department of Internal Medicine and ${ }^{2}$ Deparment of Pulmonary Diseases, Cerrahpasa Faculty of Medicine, and ${ }^{3}$ Department of Pathology, Taksim State Hospital, Istanbul, Turkey

Correspondence and reprints: Dr Cuneyt Tetikkurt, Tanzimat sok. Serkan Apt No 8/16 Caddebostan 81060, Istanbul, Turkey.

Telephone 90-216-359-60-35, fax 90-212-529-40-18, e-mail docmct@superonline.com
} 


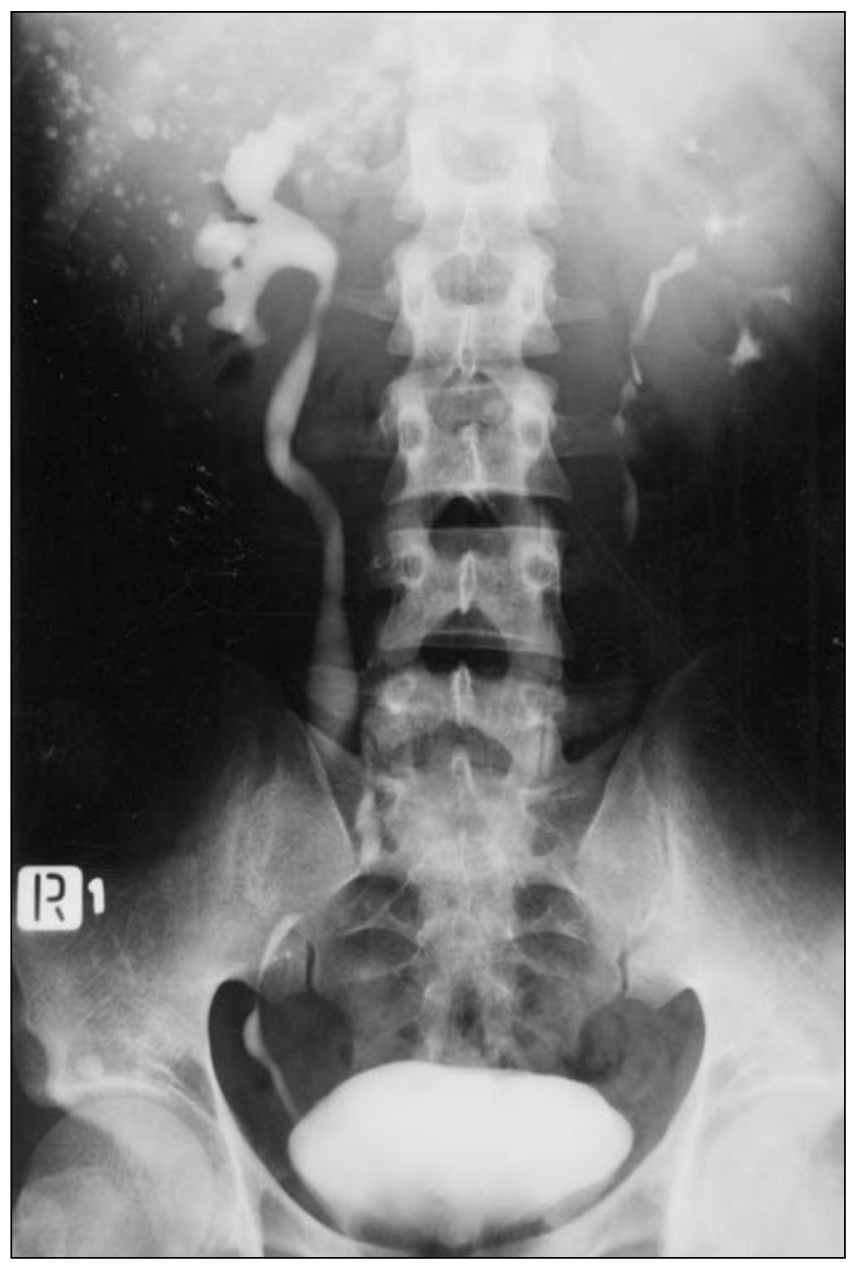

Figure 1) Intravenous pyelography radiograph showing the calcified nodules in the liver

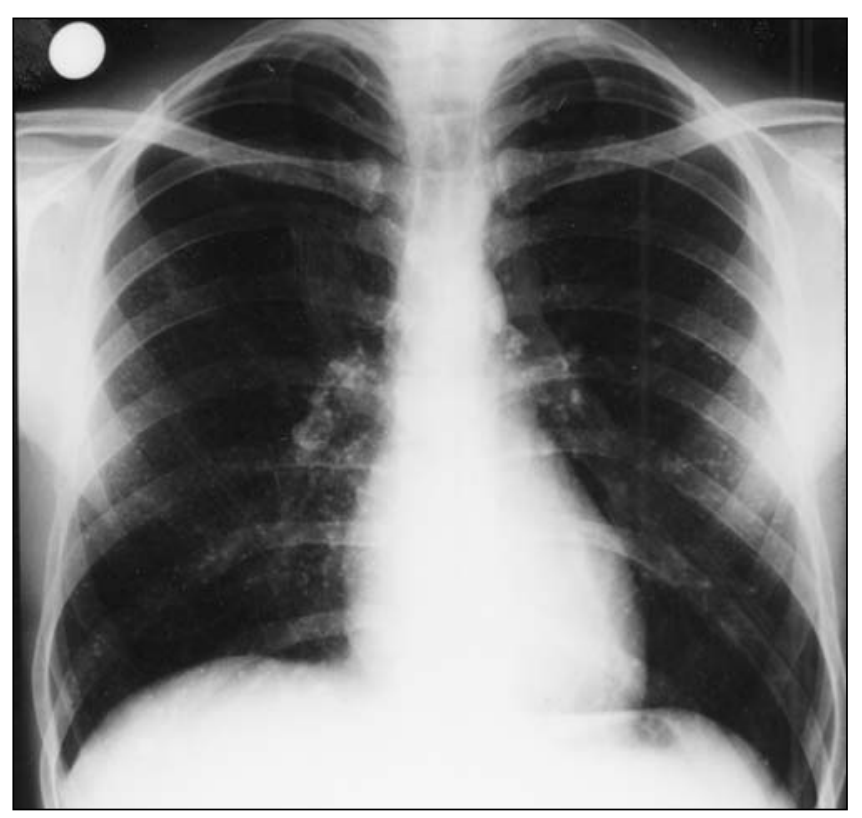

Figure 2) Chest $x$-ray showing calcified miliary nodules in both middle lung zones

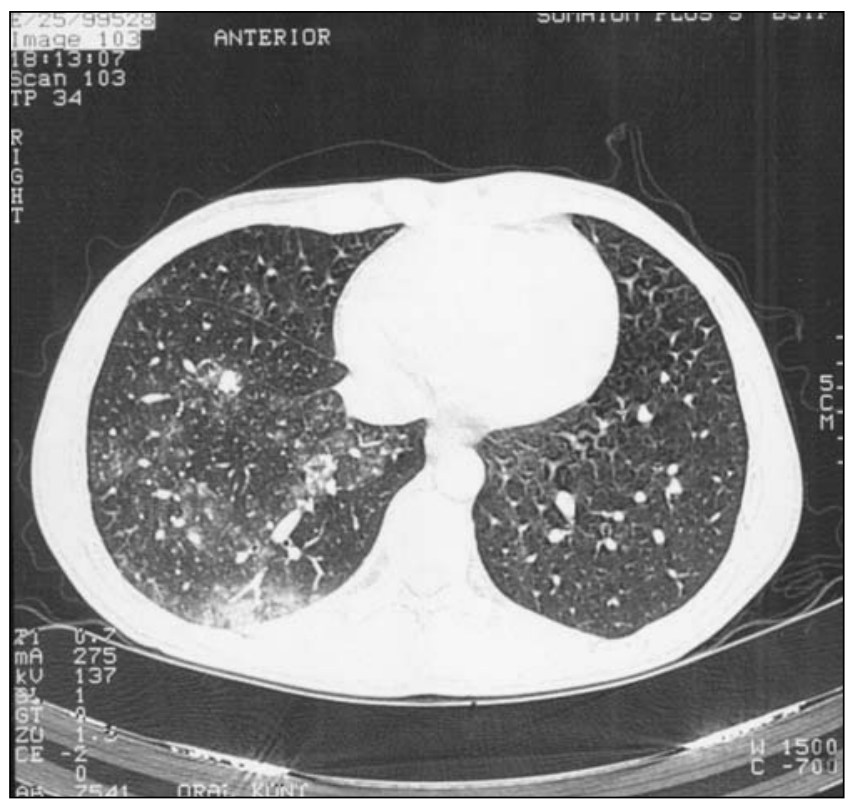

Figure 3) Computed tomography of the thorax showing calcified nodules throughout the lungs

Calcification may be found in the primary lesion, as well as in the metastatic lymph nodes, lungs and liver $(2,5)$. Because calcified metastases can strongly resemble granulomas and remain asymptomatic or stable, these conditions may be confused with sarcoidosis, tuberculosis or other infections. Diagnosis is based on the patient's history, clinical assessment, tumour markers and histopathological examination of the primary or metastatic lesion. Besides the diagnosis of medullary thyroid carcinoma, accurate determination of the extent of disease is important for the initial treatment (6).

The only clinical features that may lead the clinician to suspect medullary thyroid carcinoma are the presence of a diarrheal syndrome (7) and radiographical evidence of a calcified thyroid nodule. A patient with advanced medullary thyroid carcinoma may present with distant metastases. Our case is a sporadic medullary thyroid carcinoma because the clinical findings are not consistent with multiple endocrine neoplasia type II. The most important clue to the diagnosis was the presence of numerous calcific small nodules throughout the liver seen on the intravenous pyelography radiographs. Thorax CT confirmed the presence of miliary calcific nodules in the lungs and liver. The high serum concentrations of calcitonin and carcinoembryonic antigen also justify the diagnosis of medullary thyroid carcinoma. The diagnosis was confirmed with histopathological examination of the thyroid tissue.

In the case of calcified miliary nodules that strongly suggest granulomatous diseases, clinicians should be aware of calcification of metastases. A number of tumours may produce calcified lung or liver metastases $(8,9)$. One primary tumour causing calcified metastases is testicular carcinoma, which may be confirmed by physical examination or ultrasound. Other causes of calcified metastases are bone tumours such as osteosarcoma or chondrosarcoma, which usually produce local pain and may be diagnosed with plain films, CT, magnetic resonance imaging or 
radionuclide bone scan. Breast and gastrointestinal tumours may also metastasize as calcified nodules in the lung or liver. They usually present with local findings and are less likely to present as an occult primary tumour (10).

Metastatic disease is one of the most common causes of calcified nodules in the lung or liver. Because the metastases are detected after the primary lesion, the presumptive diagnosis of metastases from the known primary lesion is a secure diagnosis.

\section{REFERENCES}

1. Maile CW, Rodan BA, Godwin JD, Chen JT, Ravin CE. Calcification in pulmonary metastases. Br J Radiol 1982;55:108-13.

2. McDonnell CH 3rd, Fishman EK, Zerhouni EA. CT demonstration of calcified liver metastases in medullary thyroid carcinoma. J Comput Assist Tomogr 1986;10:976-8.

3. Giuffrida D, Gharib H. Current diagnosis and management of medullary thyroid carcinoma. Ann Oncol 1998;9:695-701.

4. Shaha AR, Ferlito A, Rinaldo A. Distant metastases from thyroid and parathyroid cancer. ORL J Otorhinolaryngol Relat Spec 2001;63:243-9.

5. Chariot P, Feliz A, Monet I. Miliary opacities diagnosed as lung metastases of a thyroid carcinoma after 13 years of stability. Chest $1993 ; 104: 981-2$
If there is no history of a previous tumour, then the presence of calcified nodules in the lung or liver is a diagnostic challenge for the clinician. Our case is remarkable for identifying the synchronous calcified metastasis in the lung and liver for the first time in the literature. The diagnosis of medullary thyroid carcinoma may be evident from the synchronous presence of miliary calcified nodules in two different sites if they are associated with high concentrations of serum markers.

6. Gorman B, Charboneau JW, James EM, et al. Medullary thyroid carcinoma: role of high-resolution US. Radiology 1987;162:147-50.

7. Cox TM, Fagan EA, Hillyard CJ, Allison DJ, Chadwick VS. Role of calcitonin in diarrhea associated with medullary carcinoma of the thyroid. Gut 1979;20:629-33.

8. Dahnert W. Disorders of liver, biliary tract, pancreas and spleen. In: Dahnert W, ed. Radiology Review Manual. Baltimore: Williams \& Wilkins, 1999:547-614.

9. Ferrozzi F, Rossi A. X-ray computed tomographic aspects of calcifying metastases. Apropos of 40 cases. J Radiol 1991;72:305-12.

10. Reed JC. Multiple nodules and masses. In: Reed JC, ed. Chest Radiology. St Louis: Mosby, 1997:355-69. 


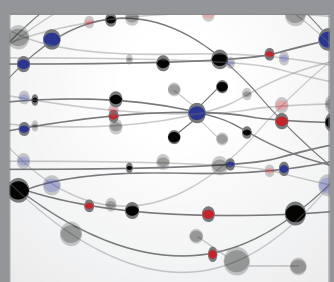

The Scientific World Journal
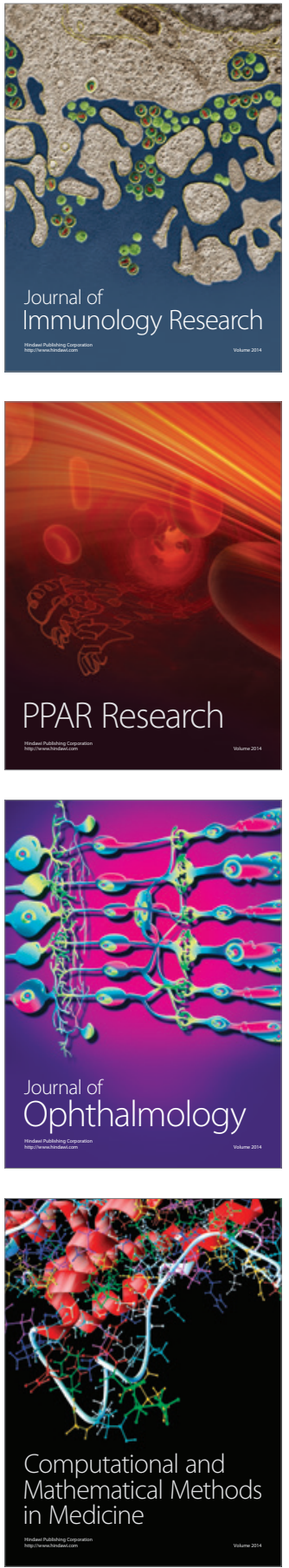

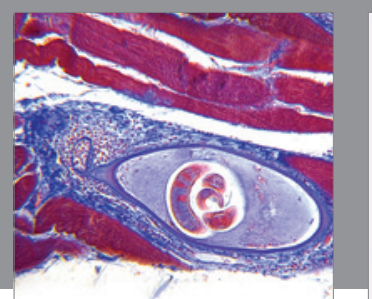

Gastroenterology Research and Practice

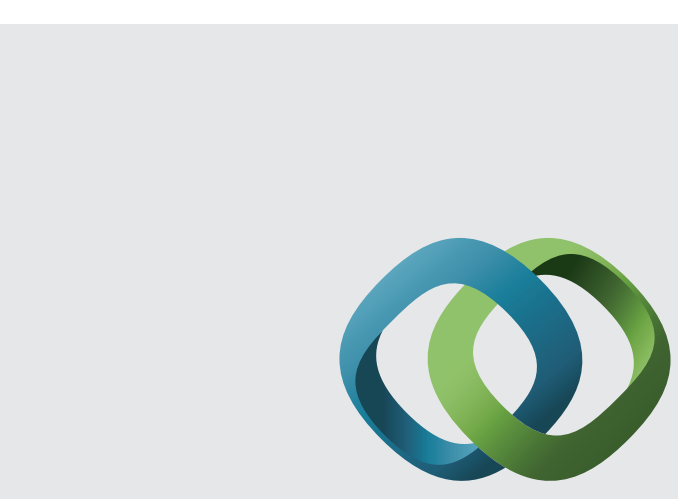

\section{Hindawi}

Submit your manuscripts at

http://www.hindawi.com
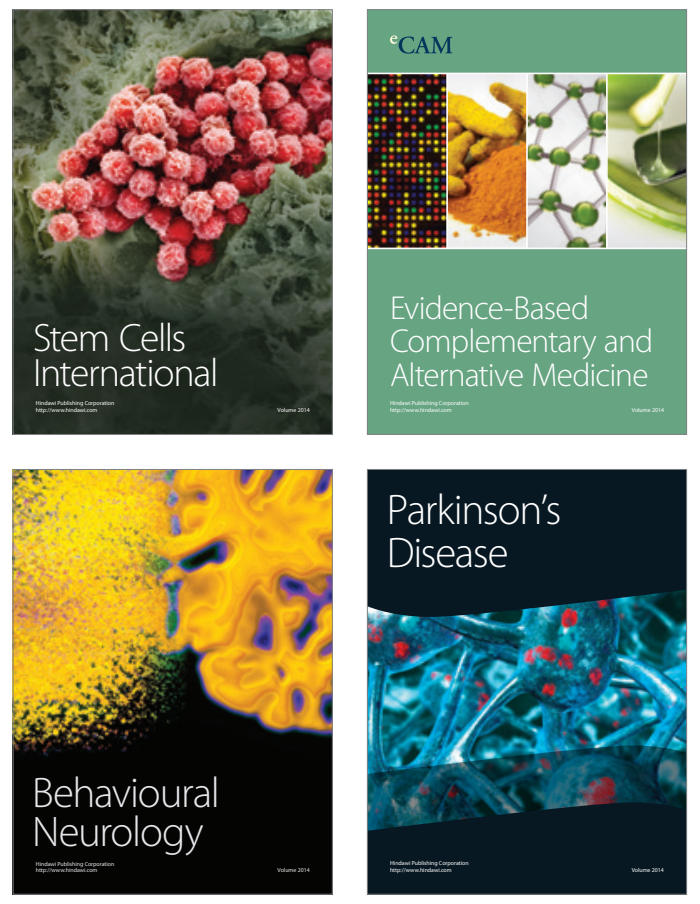
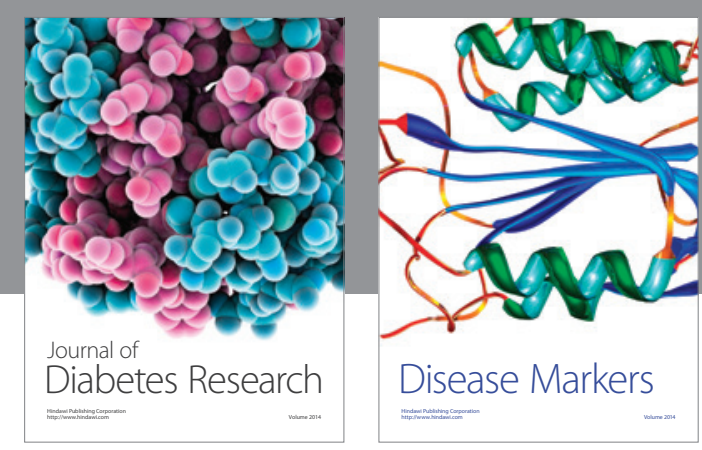

Disease Markers
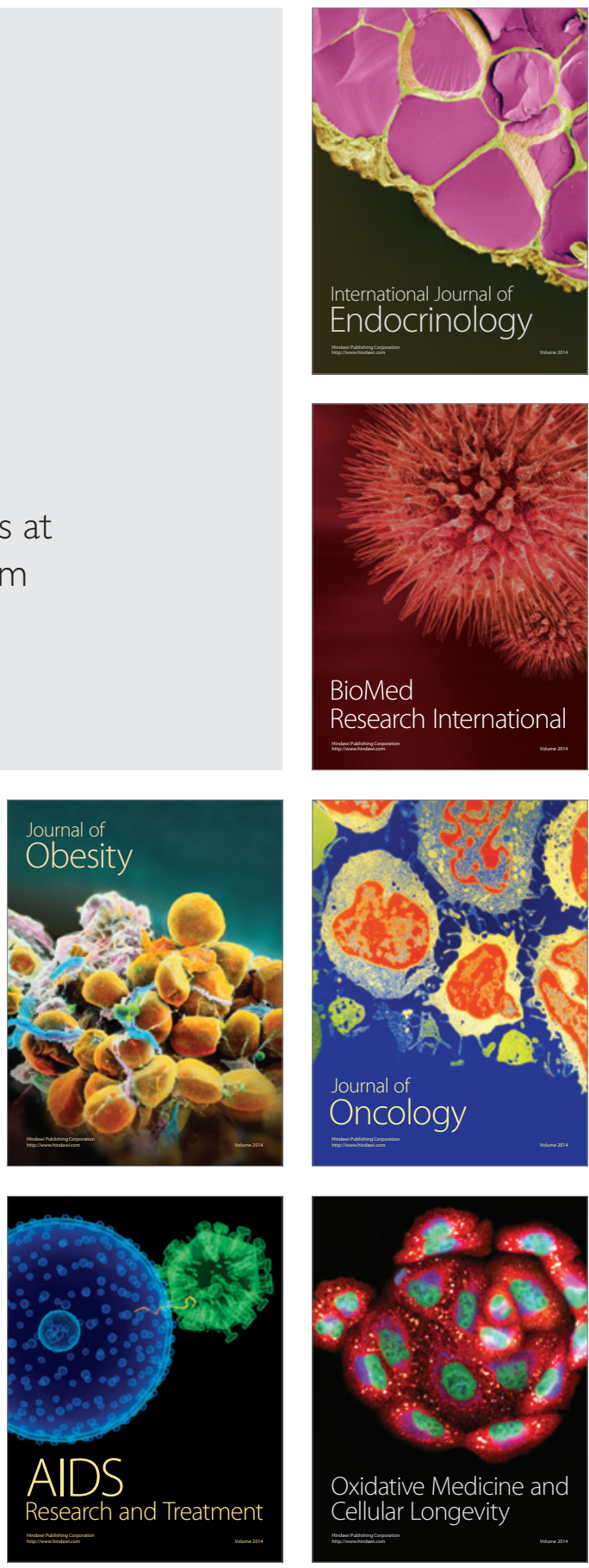